UBC 316.482

LBC 60.524

\title{
CITY CONFLICTS IN MODERN RUSSIA: A NEW ISSUE IN THE OLD CONTEXT ${ }^{1}$
}

\author{
Aleksandra V. Glukhova \\ Voronezh State University, Voronezh, Russian Federation
}

\begin{abstract}
The author notes that the political potential of sub-state formations is growing. It means that regions and cities became more powerful in public governance in the modern world. Locals become political agents on the international level. I.e. the practice of the involvement of citizens in the management process became wider (grassroots technology, where their knowledge and competencies are enough to solve many pressing problems). At the same time, in emerging conflicts, the city authorities in the West are strictly guided by the norms of the current legislation and ideas about the public good.

In Russian public policy, on the contrary, there is a lack of normal communication between the government and public groups, a respectful dialogue, and a joint search for solutions to troubling problems. The federal and city authorities, as a rule, are not interested in increasing the social activity of Russians, which does not contribute in solving conflicts. This strategy led, on the contrary, to new activism. Conflict cases in the urban community are dominated by endogenous factors, mainly based on communication defects of the urban management system. The author concludes that the key factors of urban conflict are related to the activities of local authorities, which, due to objective reasons (limited resources) and subjective reasons (inattention to the interests of citizens), do not fulfill their functions of stabilizing the socio-political area of the urban community .

Positive consequences of urban conflicts, including good communication between contractors; detente of social tension in the urban environment; development of rules and norms of interaction in a conflict situation ("rules of the game") are manifested to a much lesser extent. This creates the base for the future social and political divisions in the city. External, exogenous influences and restrictions are primarily determined by the nature resources and "the main line" of the regional policy according to the Federation. The main conflict factors are the sharp gap in the standard of living of residents of the capital and the regions, as well as the de facto colonial policy of the Center promoting "Varangians" from Moscow to the posts of regional governors and mayors, while completely ignoring the interests of local establishment and public opinion.
\end{abstract}

Key words: urban conflicts, actors, strategies, protest, political management, endogenous and exogenous factors, urban community, coordination of interests, stabilization of the socio-political public field.

УДК 316.482

ББК 60.524

\section{ГОРОДСКИЕ КОНФЛИКТЫ В СОВРЕМЕННОЙ РОССИИ: НОВАЯ ПРЕДМЕТНОСТЬ В СТАРОМ КОНТЕКСТЕ ${ }^{1}$}

\author{
Александра Викторовна Глухова \\ Воронежский государственный университет, г. Воронеж, Российская Федерация
}

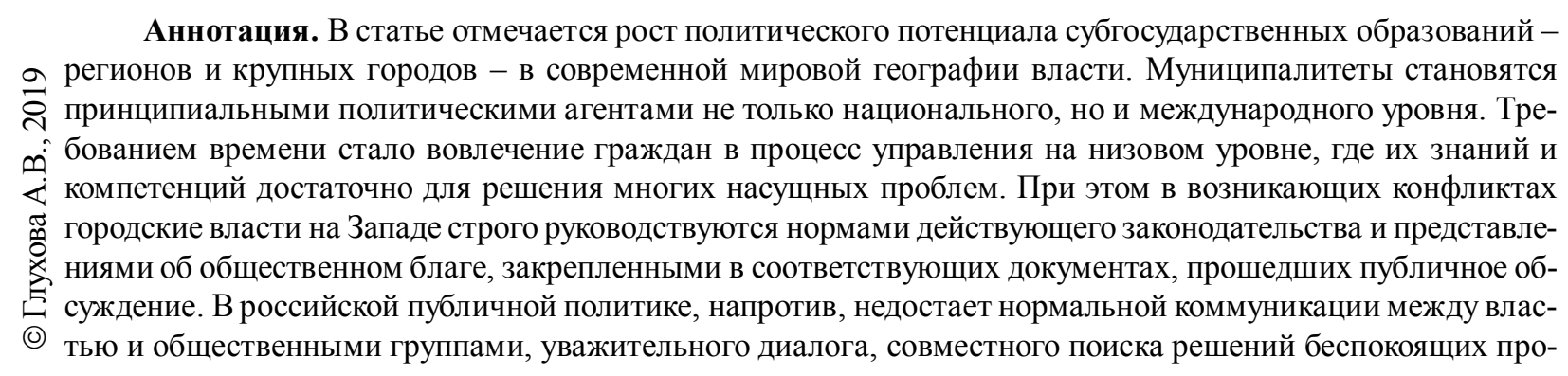


блем. Федеральные и городские власти, как правило, не заинтересованы в росте социальной активности россиян, что не способствует разрешению возникающих конфликтов, а, напротив, порождает их новую предметность. В спектре причин, провоцирующих конфликтность в городском сообществе, преобладают эндогенные факторы, касающиеся в основном дефектов коммуникативной и функциональной подсистем городской управленческой системы. Автор приходит к выводу, что ключевые факторы городской конфликтности связаны с деятельностью местных властей, которые в силу объективных оснований (ограниченность ресурсов) и субъективных причин (невнимание к интересам граждан) не выполняют свои функции по стабилизации общественно-политического пространства и координации интересов внутри городского сообщества. Конструктивные последствия городских конфликтов, включая применение технологий, улучшающих коммуникации между контрагентами; разрядку социальной напряженности в городской среде; выработку правил и норм взаимодействия в конфликтной ситуации («правил игры») проявляются в гораздо меньшей степени. По этой причине создаются предпосылки для роста напряженности и формирования социальных и политических расколов в будущем, которых вполне можно было бы избежать при условии грамотного политического управления. Внешние, экзогенные воздействия и ограничения носят преимущественно ресурсный характер и определяются региональной политикой Центра в отношении субъъектов Российской Федерации. Главными конфликтогенными факторами выступают резкий разрыв в уровне жизни жителей столицы и регионов, а также фактически колониальная политика Центра, продвигающего на должности губернаторов регионов и мэров городов «варягов» из Москвы при полном игнорировании интересов местных элит и общественного мнения.

Ключевые слова: городские конфликты, акторы, стратегии, протест, политическое управление, эндогенные и экзогенные факторы, городское сообщество, координация интересов.

Мир в первой четверти XXI в. все чаще сталкивается с феноменом формирования новых географий власти, в которых значение государственного фактора сокращается, а политический потенциал субгосударственных образований - регионов и в особенности крупнейших городов - постоянно растет [Панкевич 2013]. Мировой город начинает функционировать в принципиально иной логике, включаясь в пространственные структуры власти, построенные не только посредством национальных территорий и замкнутых государственных границ, но вокруг политико-экономических коммуникаций. Его корреспондентами становятся не только собственные национальные правительства, но и другие города, заинтересованные группы, корпоративные субъекты и т. д. В итоге муниципалитеты, которые традиционно повсеместно рассматриваются как нижний уровень управления, в случае мегаполисов становятся принципиальными политическими агентами не только национального, но и международного уровня. На смену «пространству территорий» приходит «пространство потоков» [Castells 2000] сетевых коммуникаций, повышающих значение городов.

Это ставит новые задачи перед политическим управлением: требованием времени становится вовлечение граждан в управленческий процесс, особенно на низовом уровне, где их компетенций достаточно для того, чтобы решать многие насущные проблемы. Огромный потенциал для формирования более инклюзивной политической общественности содержат в себе технические возможности Всемирной сети, делая большое количество тем предметом общественного дискурса. Тем самым повышается гибкость и «отзывчивость» политических систем различных уровней, возрастает их адаптационный потенциал по отношению ко внутренним и внешним вызовам. По мнению европейских исследователей, сегодня совершенно недостаточно лишь немного улучшить существующие структуры и системы, взятые из прошлого, и частично их обновить. Необходим подлинно новый старт, умение применить новые практики и технологии в маленьких, быстрых пилотных проектах, ведущих к большей «демократии снизу»: к большей прозрачности, вовлеченности, самоорганизации, идеальным не только для обитателей сети, но для всех граждан [Osztovics, Kovar, Fernsebner-Kokert 2017].

В последние годы для многих зарубежных стран характерно заметное укрепление конституционно-правовых гарантий функционирования органов местного самоуправления, их нормативно-правовой базы. Совершенствуется система выделения и закрепления за ними обязательных основных и частичных 
функций управления, способствующая уменьшению дублирования, более четкому определению ответственности и самостоятельности органов муниципальной системы управления. Население муниципальных образований все активнее вовлекается в сферу принятия и реализации управленческих решений. Чрезвычайно популярными становятся идеи прямой демократии, включая учреждение народных собраний на низовом уровне. Предполагается, что такие собрания могли бы сочетать в себе черты древнегреческой полисной демократии, судебную практику англосаксонских стран (например, концепцию суда присяжных) и швейцарские образцы современной прямой демократии. Высокая степень сменяемости членов таких собраний (ежемесячные выборы по жребию) унаследована из античной практики, а тесное взаимодействие с постоянными членами парламента, делегирующими на рассмотрение собрания небольшое число законопроектов, отражает современные политико-управленческие реалии. Законопроект может быть отвергнут или, напротив, утвержден собранием, которое также правомочно в выработке мер, предотвращающих возможный нажим могущественных лобби на его членов. Достоинством такого проекта является не эпизодическое, приуроченное только к выборам, но непосредственное вовлечение населения в политическую жизнь, предполагающее постоянное и заинтересованное участие [Крауч 2010]. В случае роста привлекательности подобных предложений и их практического внедрения на региональном и местном уровне народные собрания могли бы стать мощной школой гражданского воспитания, обучения навыкам политической партисипации и делиберации, формирования чувства ответственности в отношении политических вопросов.

«Именно на коммунальном и окружном уровне имеются проекты, в которых политическое самоопределение функционирует в новых форматах, пробуждающих гражданскую мотивацию. Например, строительство новой школы, где были привлечены архитекторы, бургомистр, учителя, родители, ученики - и только после этого школа была построена. Это и есть живая демократия», - отмечают австрийские исследователи [Osztovics, Kovar, Fernsebner-Kokert 2017, 57]. По их мнению, на местном уровне имеются достаточные возможности для противодействия опасной тенденции к приватизации местных общественных услуг, а также другим антисоциальным решениям местной политической элиты. Роль последней в политической жизни местных общин также должна быть ограничена, тогда как опыт и идеи простых граждан, напротив, востребованы. В том, что такие нововведения реальны, убеждает опыт ряда европейских стран (Австрии, Исландии, Германии), в которых подобные практики вполне себя оправдали.

Сказанное не означает отсутствия конфликтов в городской среде, однако позиция городских властей здесь решительная и определенная: они твердо защищают общественные интересы, используя для этого процедуры зонирования, строгого регулирования использования городской земли и т. д. Разрабатываются и применяются жесткие правила, ограничивающие владельцев участков и зданий, в частности, снос последних в случае превышения оговоренной правилами и проектом высоты. Таким образом, наряду с защитой частной собственности четко формулируется и отстаивается общественное благо, трактовки которого прошли публичное обсуждение и закреплены в соответствующих документах [Смирнягин 2007, 58-59].

Сегодня власти в сотне городов России также спешно разрабатывают стратегии программы социально-экономического развития, дающие возможность опереться на некие ориентационные показатели, заложенные в стратегические планы. Очевидно, что управлять городом в рыночных условиях несопоставимо сложнее, чем в советские времена: «...текстура города становится как бы мелкозернистой, превращаясь из привычного набора районов и кварталов в дробную мозаику домов, соседских общин и строений общего пользования, и все это со своими владельцами, нанимателями и арендаторами», - отмечает известный российский исследователь Л. Смирнягин [Смирнягин 2007, 58]. Это требует новых навыков управления, налаживания нормальной коммуникации, уважительного диалога и обмена аргументами, совместного поиска решения насущных проблем. Однако подобные навыки коммуникации не являются распространенными среди российских управ- 
ленческих структур, больше ориентированных на директивные способы реагирования на возникающие общественные проблемы. Это не способствует разрешению конфликтов, но, напротив, порождает их новую предметность и новые формы.

Прошедший 2018 г. зримо продемонстрировал, что в России происходит определенный перелом в общественном сознании, в массовом поведении, связанном с запросом на перемены. Будущее страны зависит от активности граждан, потенциал которой упирается в позицию властных институтов. Российские власти не всегда понимают характер этого вызова и пытаются сохранить все ресурсы, властные рычаги и полномочия в своих руках, препятствуя тем самым широкой общественной солидарности. Отсюда любая цель легче достигается индивидуальным, а не коллективным путем, и власть сознательно поддерживает такую ситуацию, поскольку предполагает, что с нею нужно договариваться. В связи с этим она никогда не идет на уступки широким общественным движениям, в силу чего сами такие движения постепенно исчезают по причине банальной неэффективности. Это дает основание некоторым авторам считать, что за последние годы в России практически уничтожено общество в традиционном смысле слова [Иноземцев web].

Вместе с тем предпринимаются попытки оценить потенциал «гражданского пробуждения» российского общества. По мнению К. Рогова, несмотря на то что Россия в последние годы становится все более авторитарной страной, а официальные медиа заражают телезрителей агрессивной архаикой, социальная реальность страны не исчерпывается этими явлениями. Напротив, в целом ряде измерений общество стало более модернизированным, рациональным, корпоративным. «Может ли такая модернизация сразу привести к институциональным изменениям и демократизации режима? Или напротив - авторитарные институты способны «переварить» эту естественную модернизацию, залакировав ее в глянец консьюмеризма. Это и есть едва ли не самый интересный и важный вопрос по поводу сегодняшней России» [Рогов web]. Эксперты сходятся на том, что в коллективном общественном сознании присутствуют как бы две зоны. Одна из них связана с частной жизнью, ближним кругом, решением практических задач, в том числе и общественных, но на расстоянии личной достижимости. Здесь видны явные признаки модернизации, сознательной активности, доминирует идея личной эффективности и разнообразие. Другая зона, связанная с государством и символической сферой, остается как бы «замороженной»: здесь царствует идея обращения к прошлому, лояльность традиции и эскапизм, то есть нежелание вступать в конфронтацию с «навязанными» структурами и представлениями. Вопрос в том, насколько устойчивым является этот странный дуализм и куда качнется его маятник в будущем.

Характерное для России раздвоение политического и социального сознания фиксирует и В. Пастухов. На его взгляд, люди сегодня готовы к социальному и человеческому протесту против несправедливости, но не готовы делать далеко идущие политические выводы. «Сегодня мы в Кемерово, в Волоколамске, во многих других местах видим бунтующее "путинское большинство". Но оно не понимает, что оно бунтует против системы. Оно пока не проводит пунктирную связь между системой и конкретными проявлениями общего беспорядка, который, безусловно, является следствием правового произвола» [Пастухов web].

Действительно, минувший год выявил многие «болевые точки», побуждавшие россиян открыто выражать свое несогласие с проводимой политикой. Формы этого несогласия простираются широко: от прямого участия в уличных протестах с жестким оппонированием решениям властей до инициирования серьезных кампаний в средствах массовой информации с намерением заставить чиновников пойти на уступки. Главной «болевой точкой» 2018 г. стал масштабный конфликт между властью и населением, связанный с экологической проблемой, то есть с деградацией среды обитания. География его оказалась очень широкой, практически общероссийской: Подмосковье протестовало в связи с нерешенностью «мусорной» проблемы; северные территории (Архангельск, Сыктывкар) выражали протест против предполагаемых захоронений отходов на их территориях. На протестной экологической волнев этих регионах состоялись массовые митинги, крупнейшие после распада СССР [Иноземцев web]. 
В 2019 г. социальная напряженность продолжает оставаться высокой. В течение года гражданские активисты держат оборону на станции Шиес Архангельской области, где планируется строительство заводов по переработке мусора, вывозимого из столичного мегаполиса, угрожающих уникальной экосистеме этих мест. Во Владивостоке происходили активные выступления против угольного «Терминала Астафьева», загрязняющего городской воздух; в Красноярске жители протестовали против деятельности алюминиевого завода, из-за выбросов которого в атмосферу в городе резко выросла онкологическая заболеваемость (рост более чем на четверть за последние четыре года). Существенным остается конфликтный потенциал нарушения реальных или воображаемых прав собственности граждан в связи с разного рода строительными проектами. Одним из них стала московская реновация, вызвавшая массовые митинги - самые значительные со времен московских протестов 2011-2012 гг. Во многих регионах страны серьезные конфликты возникали вокруг несанкционированных построек, которые местные власти собирались снести, а также в связи с кадастрированием земельных участков. По-прежнему в информационном пространстве сохраняется тема «обманутых дольщиков».

Эксперты обращают внимание на то, что все инфоповоды лета 2019 г. ${ }^{2}$ были созданы не властью, а обществом, что отличает актуальную ситуацию от событий десятилетней давности, когда общество вело арьергардные бои. Сегодня информационная повестка смещается в сторону тех тем, которые предлагает общество, фактически завладевшее повесткой дня.

Протесты в июле-августе 2019 г. против отказа в регистрации оппозиционным кандидатам на сентябрьских выборах в Мосгордуму также стали борьбой за политическую повестку, причем не местную, городскую, а федеральную (возможность политического представительства). Несмотря на отказ в регистрации, проблема перехвата несистемной оппозицией политической повестки была решена. Неоправданная жестокость силовых структур в процессе разгона протестантов придала общеполитической повестке мощное моральное измерение, стимулируя формирование об- щегражданского мирного протеста против государственного насилия.

Вместе с тем подобные протесты практически нигде не привели к существенному изменению властями своей позиции. Напротив, людям показывают, что в их участии в социальных процессах власти не заинтересованы. Отсюда в последующие годы протесты могут обрести новую силу и местным чиновникам все-таки придется иметь с ними дело. Тем самым политика, блокированная на федеральном уровне, спускается вниз, на локальный уровень, и люди начинают понимать, что здесь все зависит от них самих. По данным Левада-центра (октябрь 2018 г.), у россиян растет осознание ответственности за все, происходящее в стране: за 2018 г. эта цифра выросла с $9 \%$ до $28 \%$, то есть более чем в три раза. Вместе с тем только $10 \%$ респондентов считают, что могут влиять на принимаемые решения и их практическую реализацию; 62 \% утверждают, что в масштабах страны ни на что не могут повлиять [Ответственность и влияние web]. В таком случае для проявления их активности и ответственности как раз и остаются локальные площадки.

Проблему политического управления городскими конфликтами нужно рассматривать также в рамках новой парадигмы отношений между Центром и регионами и городами, встроенными в вертикаль власти. У Центра иссякают ресурсы, он сбрасывает эту проблему на регионы, а там перекладывают издержки на плечи населения. У городских властей, как и у губернатора, нет гибкости в подобных ситуациях, они оказываются заложниками давления из Центра, массированных атак со стороны интернет-сообществ, скандалов, возникающих не без участия самих чиновников и т. д. О том напряжении, которое скопилось в рамках системы управления, говорят неосторожные, а то и цинично-оскорбительные высказывания чиновников в адрес населения, которыми в последнее время переполнено публичное пространство России [Мартынов 2019].

Как показывают результаты экспертного опроса (сентябрь 2017 г.), посвященного политическому управлению городскими конфликтами в РФ, в целом в спектре причин, 
порождающих конфликтность в городском сообществе, преобладают эндогенные фак$m o p b l$, касающиеся в основном дефектов коммуникативной и функциональной подсистем городской управленческой системы [Глухова, Кольба, Соколов 2017]. Авторы исследования пришли к тому выводу, что ключевые факторы городской конфликтности связаны с деятельностью местных властей, которые в силу объективных оснований (ограниченность ресурсов) и субъективных причин (невнимание к интересам граждан) не выполняют свои функции по стабилизации общественно-политического пространства и координации интересов внутри городского сообщества. Конструктивные последствия городских конфликтов, включая применение технологий, улучшающих коммуникации между контрагентами; разрядку социальной напряженности в городской среде; выработку правил и норм взаимодействия в конфликтной ситуации («правил игры») проявляются в гораздо меньшей степени. Тем самым создаются предпосылки для роста напряженности и формирования социальных и политических расколов в будущем, которых вполне можно было бы избежать при условии грамотного политического управления.

Что касается внешних, экзогенных по отношению к городскому социуму воздействий и ограничений, они носят преимущественно ресурсный характер и определяются региональной политикой Центра в отношении субъектов РФ. В последнее время социологи все чаще фиксируют рост антимосковских настроений, вызванных как резким разрывом в уровне жизни жителей столицы и регионов, так и фактически колониальной политикой Центра, продвигающего на должности губернаторов регионов «варягов» из Москвы при полном игнорировании интересов местных элит и общественного мнения ${ }^{3}$.

Следует признать, что в посткрымском периоде центральные власти добились беспрецедентных успехов в контроле политической жизни регионов и ограничении влияния региональных элит и способны сегодня смещать даже относительно популярных губернаторов, заменяя их новыми ставленниками, не имеющими корней и связей в местных сообществах. «Этот успех был обеспечен агрессивностью репрессивных политик в отно- шении элит (хозяйственные репрессии) и высоким уровнем лояльности населения в посткрымском периоде», - считает К. Рогов [Рогов 2019, 13]. Результатом такой политики стала не только нейтрализация недовольства части региональных элитных групп, но и создание условий для экспансии федеральной олигархии на региональных рынках. Однако снижение поддержки режима, проявившееся во второй половине 2018 г. в связи с повышением пенсионного возраста и НДС, немедленно обернулось ростом «регионального патриотизма» и антимосковских настроений. «Если социальная депрессия и демобилизация лояльности будут носить затяжной характер, конфликтность региональной политики Кремля резко возрастет и превратится в один из центральных сюжетов внутриполитической жизни», - констатирует автор [Рогов 2019, 13].

Для таких оценок есть весомые основания. Как показывают социологические исследования, в сентябре 2018 г. в ряде регионов начинает проявляться феномен «снижения локуса контроля», то есть в качестве настоящей, реальной власти начинают восприниматься главы регионов и местного самоуправления [Бызов 2019]. Протестное голосование на губернаторских выборах 2018 г. в четырех регионах РФ, где победу одержали оппоненты официальных кандидатов от «Единой России», подтверждает эту тенденцию. Очевидно, что основным драйвером социального недовольства выступает экономическая ситуация и связанное с нею продолжительное падение доходов основной массы населения. В случае дальнейшего серьезного ухудшения экономического положения, сбоев в системе управления вследствие неэффективности «вертикали власти» федеральный центр может столкнуться с потерей контроля над событиями в регионах. Тем важнее в подобных ситуациях оперативная реакция региональных и местных властей на возникающие проблемы, готовность решать их совместно с обществом, с гражданскими активистами, сохраняя ситуацию в ненасильственных, институциональных рамках.

Вместе с тем существует целый ряд факторов, которые осложняют выполнение этой нелегкой задачи. В их числе ментальная самоуверенность власти, ее убежденность в 
том, что любая уступка с ее стороны воспринимается обществом как проявление слабости, чего власть ни в коем случае не может себе позволить. Другим фактором выступает элементарная неосведомленность в тонкостях публичной политики, непонимание того, с кем и каким образом нужно выстраивать переговорные коммуникации. Встроенность региональных и местных властей в управленческую властную вертикаль, укреплявшуюся, в том числе, и за счет отказа от прямых выборов мэров городов, обернулась беспомощностью местных элит в критических ситуациях, боязнью проявить инициативу там, где это крайне необходимо, неумением общаться с оппонентами в публичном поле. Властям российских городов и регионов предстоит учиться у своих западных коллег решительности в управлении, которая в советское и в постсоветское время не была им присуща.

Пока же, по мнению известного исследователя А.И. Соловьева, «в России так и не сложилась ситуация, позволявшая бы интегрировать оппозиционные партии, медиа и всех несогласных в общее русло национальной стратегии развития, в общий поток усилий по укреплению институтов власти в части имеющихся у них мандатов на управление обществом» [Соловьев 2019, 21].

Таким образом, протест как форма политического действия становится все более характерным признаком нынешней ситуации в России как на федеральном, так и на региональном, и даже локальном уровнях. Наличие новых технических возможностей в лице интернет-технологий, сетевых сообществ позволяет общественным активистам оперативно реагировать на все происходящие события, критиковать действия или бездействие властей, публично презентовать собственные позиции по любому вопросу. От властей разного уровня в современных условиях требуется столь же оперативная, аргументированная и доброжелательная реакция, содержащая конструктивные предложения по разрешению возникшей спорной проблемы. С точки зрения конфликтологической теории публичное оспаривание властных инициатив, выражение протестов в законных, институциональных формах представляет собой позитивное действие, способствующее совместному диагностированию и разрешению накопившихся проблем. Преобладание открытых форм протеста над закрытыми, латентными рассматривается как позитивное явление, как доказательство того, что публичная политика остается важным фактором развития местных сообществ.

\section{ПРИМЕЧАНИЯ}

${ }^{1}$ Исследование выполнено в рамках гранта РФФИ, проект № 19-011-00571 А «Конфликты в процессе функционирования городских сообществ крупных региональных центров России: концептуальные основания исследования и политические методы снижения деструктивного потенциала».

The study was conducted with the financial support of RFBR, project no. 19-011-00571 A "Conflicts in the process of urban communities ' functioning of large Russian regional centers: conceptual bases of research and political methods of destructive potential reduction".

${ }^{2}$ Протесты против вырубки парка в центре Екатеринбурга; пикеты против строительства мусоросжигательного завода на станции Шиес Архангельской области; дело журналиста И. Голунова, конфликт местных жителей с цыганами в Астраханской области и т. д.

${ }^{3}$ Анализ кандидатур на пост губернаторов показал, что 60 \% назначенцев 2018-2019 гг. - «варяги», то есть чиновники, не имевшие никакой связи с регионом назначения в предшествующий период.

\section{СПИСОК ЛИТЕРАТУРЫ}

Бызов 2019 - Бызов Л.Г. От расцвета к упадку. Ценностное измерение пугинской эпохи (20002018) // Свободная мысль. 2019. № 2. С. 49-64.

Глухова, Кольба, Соколов 2017 - Глухова А.В., Кольба А.И., Соколов А.В. Политико-институциональные и коммуникативные аспекты взаимодействия субъектов городских конфликтов (по материалам экспертного опроса) // Человек. Общество. Управление. 2017. № 4. С. 44-65.

Иноземцев web-Иноземцев $B$. Почему конфликты народа с властью не ведут к общероссийскому протесту [Открытые медиа. 07.01.2019] // https://openmedia.io/news/ pochemu-konflikty-naroda-s-vlastyu-nevedut-k-obshherossijskomu-protestu.

Крауч 2000 - Крауч К. Постдемократия. М.: Изд. дом Гос. ун-та - Высш. шк. экон., 2010.

Мартынов 2019 - Мартынов К. Перехват хамства. Пропаганда начала использовать ненависть 
россиян к чиновникам // Новая газета. 2019. 18 янв. (№ 5 ). С. 2.

Ответственность и влияние web - Ответственность и влияние [Опрос Левада-центра. Пресс-выпуск 31.10.2018] // https://www.levada.ru/2018/ 10/31/otvetstvennost-i-vliyanie-2.

Панкевич 2013 - Панкевич Н.В. Политическая стратегия российской урбанизации: от мировых городов к национальной сетевой платформе // Политические исследования. 2013. № 1. С. 72-85.

Пастухов web-Пастухов В.Б. Персонально ваш. [Эхо Москвы. 30 марта 2018 г.] // https://echo.msk.ru/ programs/personalnovash/2173542-echo.

Рогов web - Рогов K. Низовая модернизация в России - существует ли она и что это означает? // https://echo.msk.ru/blog/rogov_k/ 2326517-echo.

Рогов 2019 - Рогов K. Дрейф на льдине, похожей на Крым// Новая газета. 2019. 9 янв. (№ 1). С. 11-13.

Смирнягин 2007 - Смирнягин Л. Трудное будущее российских городов // Pro et contra 2007. № 1. C. 56-71.

Соловьев 2019 - Соловьев А.И. Политическая повестка правительства, или зачем государству общество // Политические исследования. 2019. № 4. C. 8-25. DOI: 10.17976/jpps/2019.04.02.

Castells 2000 - Castells $M$. The Information Age: Economy, Society and Culture. Vol. 1: The Rise of the Network Society, $2^{\text {nd }}$ ed. Oxford: Blackwell, 2000.

Osztovics, Kovar, Fernsebner-Kokert 2017 - Osztovics W., Kovar A., Fernsebner-Kokert B. Arena Analyse 2017: Demokratieneustarten. Wien: Koverent Partners, 2017.

\section{REFERENCES}

Byzov L.G., 2019. From heyday to decline. The Value Dimension of the Putin era (2000-2018) // Svobodnaya mysl, no 2, pp. 49-64.

Glukhova A. V., Kol'ba A.I., Sokolov A., 2017. Politicalinstitutional and communicative aspects of interaction of subject of urban conflicts (based on expert survey). Man. Society. Management, no. 4, pp. 44-65.

Inozemtsev V., 2019. Why conflicts of the people with the power do not lead to the all-Russian protest. Open media, 07.01.2019. URL: https:// openmedia.io/news/pochemu-konflikty-narodas-vlastyu-ne-vedut-k-obshherossijskomuprotestu (accessed 20 March 2019).

Crouch C., 2010. Post-Democracy. Moscow, State University - Higher School of Economy Press.

Martynov K., 2019. Interception of rudeness. Propaganda began to use the hatred of Russians to officials. Novaya Gazeta, 18 Jan. (no. 5), p. 2

The responsibility and influence, 2018. A survey by "Levada Center". Press release 31.10.2018. URL: https:/www.levada.ru/2018/10/31/otvetstvennosti-vliyanie-2 (accessed 20 March 2019).

Pankevich N.V., 2013. Political strategy of Russian urbanization: from world cities to national network platform. Political studies, no. 1, pp. 72-85.

Pastukhov V. B. Personally your. Echo of Moscow, 30 March 2018. URL: https://echo.msk.ru/ programs/personalnovash/2173542-echo (accessed 20 March 2019).

Rogov K. Grassroots modernization in Russia - does it exist and what does it mean? URL: https:// echo.msk.ru/blog/rogov_k/2326517-echo (accessed 20 March 2019).

Rogov K., 2019. Drift on an ice floe, similar to the Crimea. Novaya Gazeta, 9 Jan. (no. 1), pp. 11-13.

Smirnyagin L., 2007. Difficult future of Russian cities. Pro et contra, no. 1. pp. 56-71.

Solovyov A.I., 2019. Political agenda of the government, or why the state needs the society. Political Studies, no. 4, pp. 8-25. DOI: 10.17976/ jpps/2019.04.02.

Castells M., 2000. The Information Age: Economy, Society and Culture. Vol. 1: The Rise of the Network Society, $2^{\text {nd }}$ ed. Oxford, Blackwell.

Osztovics W., Kovar A., Fernsebner-Kokert B., 2017. Arena Analyse 2017: Demokratieneustarten. Wien, Koverent Partners.

\section{Information about the Author}

Aleksandra V. Glukhova, Doctor of Sciences (Politics), Professor, Head of the Department of Sociology and Political Science, Voronezh State University, Universitetskaya Sq., 1, 394016 Voronezh, Russian Federation, soc@hist.vsu.ru, https://orcid.org/0000-0002-3894-3229

\section{Информация об авторе}

Александра Викторовна Глухова, доктор политических наук, профессор, заведующая кафедрой социологии и политологии, Воронежский государственный университет, Университетская пл., 1,394016 г. Воронеж, Российская Федерация, soc@hist.vsu.ru, https://orcid.org/0000-0002-3894-3229 